\title{
MGDG extracted from spinach enhances the cytotoxicity of radiation in pancreatic cancer cells
}

Hiroaki Akasaka', Yoshiyuki Mizushina ${ }^{2}, K^{1}$ Kenji Yoshida ${ }^{1}$, Yasuo Ejima ${ }^{1}$, Naritoshi Mukumoto', Tianyuan Wang ${ }^{1}$, Sachiko Inubushi ${ }^{1}$, Masao Nakayama ${ }^{1}$, Yuki Wakahara ${ }^{1}$ and Ryohei Sasaki ${ }^{*}$

\begin{abstract}
Background: In our previous study, monogalactosyl diacylglycerol (MGDG) purified from spinach was found to have cytotoxic effects in human cancer cell lines. This study further assessed whether MGDG can enhance the cytotoxic effects of radiation in human pancreatic cancer cells in vitro and in vivo.
\end{abstract}

Methods: Glycoglycerolipids from spinach including MGDG were extracted from dried spinach. The cytotoxicity of MGDG were evaluated by the MTT assay using four human pancreatic cancer cell lines (MIAPaCa-2, AsPC-1, BxPC-3 and PANC-1) and normal human dermal fibroblasts (NHDFs). The effects of radiation and MGDG alone or in combination in MIAPaCa-2 cells was analyzed with the colony forming and apoptosis assays, western blotting and cell cycle and DNA damage analyses ( $\mathrm{Y}-\mathrm{H} 2 \mathrm{AX}$ foci staining and comet assay). The inhibitory effects on tumor growth were assessed in a mouse xenograft tumor model.

Results: MGDG showed dose- and time-dependent cytotoxicity, with half-maximal inhibitory concentrations $\left(\mathrm{IC}_{50}\right)$ in PANC-1, BxPC-3, MIAPaCa-2 and AsPC-1 cells at $72 \mathrm{~h}$ of $25.6 \pm 2.5,26.9 \pm 1.3,18.5 \pm 1.7$, and $22.7 \pm 1.9 \mu \mathrm{M}$, respectively. The colony forming assay revealed fewer MIAPaCa-2, BxPC-3 and AsPC-1 cell colonies upon treatment with both MGDG and radiation as compared to irradiation alone $(P<0.05)$. The combination of MGDG and radiation induced a higher proportion of apoptosis in MIAPaCa-2 cells; this effect was associated with increased mitochondrial release of cytochrome $c$ and activation of cleaved poly (ADP-ribose) polymerase and caspase-3. DNA damage was detected and DNA repair mechanisms were more frequently impaired in cells receiving the combination treatment as compared to either one alone. Tumor growth was inhibited to a greater degree in mice treated by intratumoral injection of MGDG combined with irradiation as compared to either one alone $(P<0.05)$.

Conclusions: This is the first report demonstrating that MGDG enhances the cytotoxicity of radiation to induce apoptosis of cancer cells in vitro and in vivo. Our findings indicate that this therapeutic combination can be an effective strategy for the treatment of pancreatic cancer.

Keywords: Monogalactosyl diacylglycerol (MGDG), Radiation, Pancreatic cancer, Radiosensitizer, Apoptosis

\footnotetext{
*Correspondence: rsasaki@med.kobe-u.ac.jp

'Division of Radiation Oncology, Kobe University Graduate School of

Medicine, Chuo-ku, Kobe, Hyogo 650-0017, Japan

Full list of author information is available at the end of the article
} 


\section{Background}

Pancreatic cancer remains a major public health issue as the third leading cause of cancer-related death in Europe, the fourth in the United States, and the fifth (men) or sixth (women) in Japan [1-3]. Recent in vitro and in vivo studies have shown that consumption of vegetables and fruits with chemopreventive components can reduce cancer risk [4-6]. The chloroplast thylakoid membrane of higher plants contains glycoglycerolipids such as monogalactosyl diacylglycerol (MGDG), digalactosyl diacylglycerol (DGDG) and sulfoquinovosyl diacylglycerol (SQDG) [7]; these compounds have potential anti-cancer functions including inhibition of DNA polymerase and suppression of cancer cell proliferation [8], with MGDG showing more potent anti-tumorigenic and anti-inflammatory activity than the others [9]. Spinach is a major source of glycoglycerolipids and has the highest MGDG content among vegetables, fruits and grains tested to date [10-12].

Various approaches have been used to improve the survival rate of pancreatic cancer patients, including adjuvant chemotherapy [13-15], preoperative chemoradiotherapy [16-18], and induction chemotherapy followed by chemoradiotherapy $[19,20]$. Our previous study showed that MGDG enhanced the cytotoxic effects of gemcitabine (GEM) - a key drug for treating pancreatic cancer-possibly by selectively inhibiting mammalian replicative DNA polymerases, specifically pol $\gamma$ [21].

The present study further investigated whether MGDG might enhance the effects of radiation on human pancreatic cancer cell lines in vitro and in vivo.

\section{Methods}

\section{Isolation of MGDG from spinach}

The spinach (Spinacia oleracea) subspecies Anna was used in this study. Dried spinach was extracted with ethanol; the extract was diluted in $70 \%$ aqueous ethanol and subjected to Diaion HP-20 column chromatography (Sigma-Aldrich, St. Louis, MO, USA), then eluted with 95\% aqueous ethanol. The eluate was evaporated to dryness; the residue was redissolved in chloroform and the resultant solution was subjected to PSQ60B silica gel column chromatography (Fuji Silysia Chemical, Tokyo, Japan). After washing with chloroform/ethyl acetate $(1: 1 \mathrm{v} / \mathrm{v})$, the column was eluted with ethyl acetate and the eluate was purified using a Sep-Pak $\mathrm{C}_{18}$ cartridge (Waters, Milford, MA, USA) that was then eluted with methanol. The MGDG fraction was evaporated, yielding pure MGDG ( 98\%). The purity was confirmed by normal-phase silica gel high-performance liquid chromatography (Shiseido, Tokyo, Japan) coupled to an evaporative light scattering detector (M\&S Instruments, Osaka, Japan), with chloroform/methanol $(1 / 1, \mathrm{v} / \mathrm{v})$ used as the eluent.
Cell culture and viability assessment

MIAPaCa-2, PANC-1, BxPC-3 and AsPC-1 human pancreatic cancer cell lines as well as Raji and HL60 cells were obtained from the American Type Culture Collection (Manassas, VA, USA) and cultured in Roswell Park Memorial Institute 1640 medium supplemented with $10 \%$ fetal bovine serum, penicillin $(100 \mathrm{U} / \mathrm{ml})$, streptomycin $(100 \mu \mathrm{g} / \mathrm{ml})$. HCT116 colon carcinoma cell lines with wild-type p53 (HCT116 p53 $\left.3^{+/+}\right)$and their isogenic derivatives lacking p53 (HCT116 p53 ${ }^{-/-}$) were a gift from Dr. Bert Vogelstein (Johns Hopkins University, Baltimore, MD, USA). The cells were maintained in McCoy's 5A medium. Primary normal human dermal fibroblasts (NHDFs) were purchased from Cell Systems Corp. (Kirkland, WA, USA) and maintained according to the supplier's instructions. The cytotoxicity of MGDG was evaluated with the 3-(4, 5-dimethylthiazol-2-yl)-2, 5diphenyltetrazolium bromide (MTT) assay. The cytotoxicity when combined with irradiation was assessed with the colony forming assay. For the MTT assay, cells were treated with $0,2,5,10,20,50$ or $100 \mu \mathrm{M}$ MGDG or corresponding doses of dimethyl sulfoxide (DMSO) for 24, 48 or $72 \mathrm{~h}$ at $37{ }^{\circ} \mathrm{C}$ in a humidified atmosphere of $5 \%$ $\mathrm{CO}_{2} ; 2 \mathrm{~h}$ after adding MTT solution $(0.6 \mathrm{mg} / \mathrm{ml}$ in MilliQ-purified water), cells were lysed in $200 \mu \mathrm{l}$ of fresh DMSO. For the colony forming assay, MIAPaCa-2, BxPC-3 and AsPC-1 cells were treated with 40-60 $\mu \mathrm{M}$ MGDG or $0.8 \%$ DMSO for $24 \mathrm{~h}$, and then exposed to 0 , 2, 4 and 8 Gy of radiation. After 9-12 days, colonies were fixed with a solution of $10 \%$ methanol and $20 \%$ acetic acid, stained with Methylene Blue and counted under a light microscope.

\section{X-ray irradiation}

X-ray irradiation was performed using a MBR-1505R2 instrument (Hitachi, Tokyo, Japan) at a voltage of $150 \mathrm{kV}$ and a current of $5 \mathrm{~mA}$ with a 1-mm-thick aluminum filter $(0.5 \mathrm{~Gy} / \mathrm{min}$ at the target $)$ for in vitro and in vivo studies. Mice were anesthetized by intraperitoneal administration of somnopentyl $(0.1 \mathrm{mg} / \mathrm{g}$ body weight) and were then anesthetized and immobilized in a customized harness that exposed the implanted tumors while shielding the remainder of the body with lead during irradiation.

\section{Analysis of apoptotic cells}

Apoptosis was evaluated based on DNA fragmentation using the APO-Direct Assay Staining kit (BD Biosciences, San Diego, CA, USA) as previously described [22]. In this assay, DNA breaks are labeled with fluorescein isothiocyanate (FITC)-2' -deoxyuridine-5' ${ }^{\prime}$-triphosphate and cells are analyzed by flow cytometry. MIAPaCa-2 cells were treated with MGDG $(25 \mu \mathrm{M})$ alone for $24 \mathrm{~h}$, radiation (5 Gy) alone for $12 \mathrm{~h}$, or with a 
combination of both. The cells were harvested by trypsinization, washed with phosphate-buffered saline (PBS), and then fixed in $1 \%$ paraformaldehyde for $15 \mathrm{~min}$ followed by $70 \%$ ethanol overnight at $-20{ }^{\circ} \mathrm{C}$. A DNA labeling solution containing FITC was added for $30 \mathrm{~min}$; the cells were the resuspended in PBS, and apoptosis was detected by flow cytometry on a FACS Calibur instrument (Becton Dickinson, Franklin Lakes, NJ, USA). Data were analyzed with CellQuest software (Becton Dickinson), and apoptotic cells were quantified as a percentage of the total number of cells.

\section{Western blot analysis}

MIAPaCa-2 cells were seeded at a density of $2 \times 10^{6}$ / well in a 6-well plate for $24 \mathrm{~h}$, then washed with PBS and incubated with various concentrations of MGDG for $24 \mathrm{~h}$. Cells were washed twice with PBS and lysed in lysis buffer composed of $20 \mathrm{mM}$ HEPES (pH 7.5), 10\% glycerol, $1.5 \mathrm{mM} \mathrm{MgCl}, 1 \mathrm{mM}$ TritonX-100, and protease inhibitor cocktail (Roche Life Science, Tokyo, Japan) followed by boiling for $5 \mathrm{~min}$. To isolate cytosolic and mitochondrial fractions, MIAPaCa-2 cells were harvested by scraping on ice, and resuspended in $500 \mu \mathrm{l}$ buffer A composed of $20 \mathrm{mM}$ HEPES (pH 7.5), $10 \mathrm{mM}$ $\mathrm{KCl}, 1.5 \mathrm{mM} \mathrm{MgCl} 2,1 \mathrm{mM}$ EDTA, $1 \mathrm{mM}$ EGTA, and protease inhibitor cocktail. After incubation on ice for $1 \mathrm{~h}$, cells were lysed by repeated passage (20-30 times) through a 27 -gauge needle. The lysates were centrifuged at $750 \times g$ for $5 \mathrm{~min}$ at $4{ }^{\circ} \mathrm{C}$ and the supernatant was centrifuged at $10,000 \times g$ for $15 \mathrm{~min}$ at $4{ }^{\circ} \mathrm{C}$. The mitochondrial pellet was washed once in buffer $\mathrm{A}$ and lysed in Laemmli sample buffer. The supernatant was centrifuged at $100,000 \times g$ for $30 \mathrm{~min}$ at $4{ }^{\circ} \mathrm{C}$ to obtain the cytosolic fraction. Protein concentrations were measured with the bicinchoninic acid protein assay kit (Pierce Biotechnology, Rockford, IL, USA) according to the manufacturer's protocol. Proteins were separated by sodium dodecyl sulfate-polyacrylamide gel electrophoresis and then transferred to nitrocellulose membranes that were blocked with 5\% non-fat milk in PBS and probed overnight at $4{ }^{\circ} \mathrm{C}$ with primary antibodies against the following proteins: actin (Santa Cruz Biotechnology, Dallas, TX, USA), poly (ADP-ribose) polymerase (PARP) (Cell Signaling Technology, Danvers, MA, USA), caspase-3 (Cell Signaling Technology), pro-caspase-3 (GeneTex, Irvine, CA, USA), B cell lymphoma (Bcl)-2 (Santa Cruz Biotechnology), and Bcl-2-associated X protein (Bax) (Santa Cruz Biotechnology). Immunoreactivity was detected with an enhanced chemiluminescence kit (GE Healthcare, Little Chalfont, UK) and protein bands were visualized using an Amersham Imager 600 (GE Healthcare). Signal intensity was quantified using Multi Gauge v.3.0 software (Fujifilm, Tokyo, Japan).

\section{Cell cycle analysis}

The effect of MGDG on the cell cycle was evaluated by flow cytometry as previously described [23]. Briefly, MIAPaCa- 2 cells $\left(3 \times 10^{5}\right.$ cells in a $25-\mathrm{ml}$ flask $)$ were treated with $40 \mu \mathrm{M}$ MGDG, 8 Gy of radiation, or a combination of both for $24 \mathrm{~h}$. Cells were irradiated within $12 \mathrm{~h}$ of adding MGDG and incubated for $12 \mathrm{~h}$, then fixed on ice for 30min in PBS (pH 7.4) containing $2 \%$ formaldehyde and stored at $-20{ }^{\circ} \mathrm{C}$ until analysis. Cells were washed and incubated for $15 \mathrm{~min}$ in phosphate citric acid buffer composed of $20 \%$ Triton X and $5 \mathrm{mg} / \mathrm{ml}$ ribonuclease A in PBS, then resuspended in $50 \mathrm{mg} / \mathrm{ml}$ propidium iodide for at least $15 \mathrm{~min}$ at room temperature in the dark; the DNA content of the samples was analyzed by flow cytometry using a FACScan instrument (Becton Dickinson) with a 488-nm laser run at $15 \mathrm{~mW}$ and a 585/420-nm bandpass filter. At least 20,000 events were acquired using CellQuest software (Becton Dickinson). The experiment was performed at least twice. The G1, S and G2 fractions were identified by selecting the areas consisting of living cells and excluding those containing dead cells.

\section{Detection of DNA damage in vitro}

Induction of DNA damage was investigated by detecting phosphorylated histone 2AX $(\gamma-\mathrm{H} 2 \mathrm{AX})$-positive foci by immunocytochemistry [24]. Briefly, MIAPaCa-2 cells were subcultured in $35-\mathrm{mm}$ dishes and treated with $40 \mu \mathrm{M}$ MGDG for $1 \mathrm{~h}$ and/or 8 Gy of radiation. Cells were then fixed in $4 \%$ paraformaldehyde in PBS for 20min, permeabilized with $0.1 \%$ Triton X-100 in PBS for $5 \mathrm{~min}$, and blocked in 5\% bovine serum albumin in PBS for $60 \mathrm{~min}$. The cells were incubated with rabbit anti $\gamma$ H2AX antibody (1:200; Cell Signaling Technology, Danvers, MA, US) overnight at $4{ }^{\circ} \mathrm{C}$, followed by incubation with tetramethyl rhodamine isothiocyanate-conjugated anti-rabbit secondary antibody (1:20; Dako, Glostrup, Denmark) for $90 \mathrm{~min}$ at room temperature. Nuclei were

Table 1 Cytotoxic effects of glycoglycerolipids from the spinach on human cancer cell growth

\begin{tabular}{|c|c|c|c|c|}
\hline \multirow[b]{2}{*}{ Cell type } & \multirow[b]{2}{*}{ Tissue origin } & \multicolumn{3}{|c|}{$\mathrm{IC}_{50}(\mu \mathrm{M})$} \\
\hline & & $\overline{\mathrm{DGDG}}$ & SQDG & $\overline{M G D G}$ \\
\hline HCT116 p53 & Colon & 22 & 78 & 13 \\
\hline НСТ116 $\mathrm{p}^{-/-}$ & Colon & 30 & 180 & 16 \\
\hline HL60 & Leukemia & 27 & 144 & 5 \\
\hline Raji & Lymphoma & 22 & 114 & 5 \\
\hline PANC-1 & Pancreas & 103 & 48 & 11 \\
\hline MIAPaCa-2 & Pancreas & 16 & 66 & 4 \\
\hline Median & & 26 & 96 & 8 \\
\hline
\end{tabular}

DGDG digalactosyl diacylglycerol, $I C_{50}$ half-maximal (50\%) inhibitory concentration, MGDG monogalactosyl diacylglycerol, SQDG sulfoquinovosyl diacylglycerol 
stained with 4',6-diaidino-2- phenylindole, and cells were visualized with a fluorescence microscope (BZ-9000; Keyence, Osaka, Japan). Nuclear $\gamma$-H2AX foci in 200 cells in each treatment group were manually counted, and data are presented as the mean \pm standard deviation of three random fields.

\section{Comet assay for detection of DNA repair impairment}

The alkaline comet assay was performed using a kit (Trevigen, Gaithersburg, MD, USA) according to the manufacturer's instructions. Briefly, $250 \mathrm{ml}$ of $0.65 \%$ normal agarose was prepared and a drop was placed on a frosted slide, covered with a coverslip and allowed to solidify. The cell suspension $(100 \mathrm{ml})$ was mixed at 1:10 with $0.5 \%$ low-melting-point agarose and a $100 \mu \mathrm{l}$ volume of the mixture was pipetted onto the slides and allowed to solidify. A final layer of $0.5 \%$ low-meltingpoint agarose was added, and slides were then immersed for $1 \mathrm{~h}$ at $4{ }^{\circ} \mathrm{C}$ in the dark in cold lysis solution composed of $2.5 \mathrm{M} \mathrm{NaCl}, 100 \mathrm{mM}$ EDTA, $300 \mathrm{mM} \mathrm{NaOH}$, $10 \mathrm{mM}$ Tris, and $34 \mathrm{mM} \mathrm{N}$-lauroylsarcosine $(\mathrm{pH} \mathrm{10})$, with $10 \%$ DMSO and $1 \%$ Triton X-100 added just before use. Slides were placed in a submarine-type electrophoresis tank containing $300 \mathrm{mM} \mathrm{NaOH}$ and $1 \mathrm{mM}$ EDTA $(\mathrm{pH} 13.5)$ for $15 \mathrm{~min}$. Electrophoresis was then carried out at $0.8 \mathrm{~V} / \mathrm{cm}$ for $15 \mathrm{~min}$. Slides were rinsed three
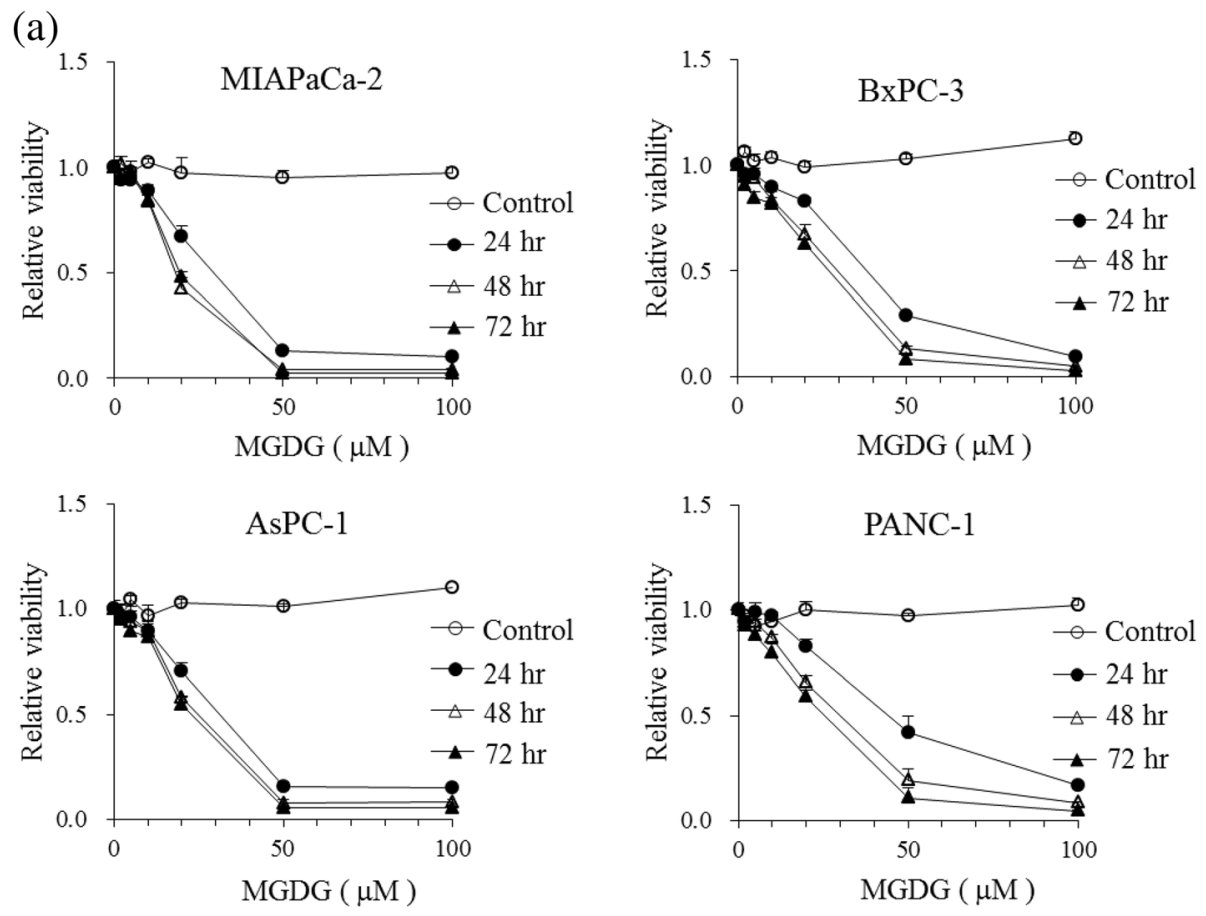

(b)

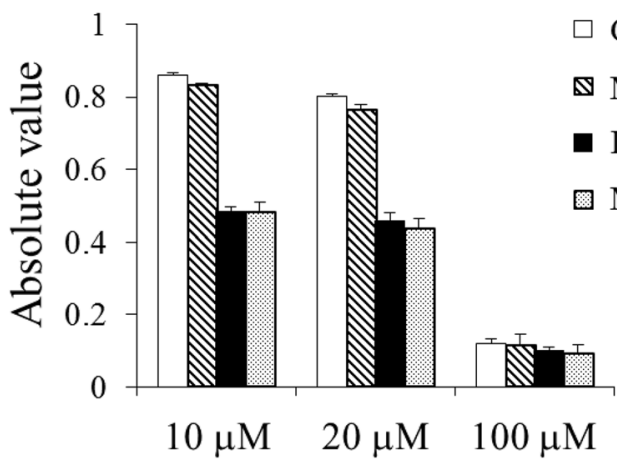

Control

MGDG

Irradiation

MGDG + irradiation

\section{Concentration of MGDG}

Fig. 1 a Cytotoxic effects of MGDG on four human pancreatic cancer cells, as determined by the MTT assay. b Effects of MGDG, radiation and their combination on NHDFs, as evaluated by the MTT assay 
times with neutralization buffer (0.5 M Tris, $\mathrm{pH} 7.4)$ and stained with a solution of $1 \mu \mathrm{l}$ SYBR Green Gold in $30 \mathrm{ml}$ Tris/EDTA buffer.

\section{Evaluation of in vivo tumor growth-inhibitory effect}

Male BALB/cAJcl-nu/nu mice (4 weeks old; $n=10$ per group) were used for the xenograft model. Experiments were carried out in strict accordance with institutional ethics guidelines. Each mouse received a subcutaneous intratumoral injection of $2 \times 10^{7} \mathrm{MIAPaCa}-2$ cells resuspended in the Matrigel (BD Biosciences) and were then randomly divided into the following four groups: control, MGDG (injection with $2 \mathrm{mg}$ MGDG solution twice on alternate days to ensure good penetration into the tumors), irradiation (5 Gy), and the combination of both. For this procedure, MGDG was used at a concentration of $50 \mathrm{mg} / \mathrm{ml}(62.5 \mathrm{mM})$ in solvent, and $4 \mathrm{mg}$ MGDG solution (two injections of 2-mg MGDG solution) were used to prepare $50 \mu \mathrm{M}$ MGDG. To assess the tumor growth-inhibitory effect of MGDG and/or radiation, tumor size was measured two or three times a week by calculating the volume using the formula $\mathrm{L} \times \mathrm{W}^{2} \times(\pi / 6)$, where $\mathrm{L}$ and $\mathrm{W}$ are the longest and shortest diameters of the tumor, respectively. All animal experiments were approved by the Institutional Animal Care and Use Committee (permission no. 100605R1) and were performed according to Kobe University Animal Experimentation Regulations.

\section{Statistical analysis}

Data are presented as mean \pm standard error. Differences between groups were evaluated with the Student's $t$ test. Data were considered statistically significant at $P<0.05$. (a)

\section{MIAPaCa-2}

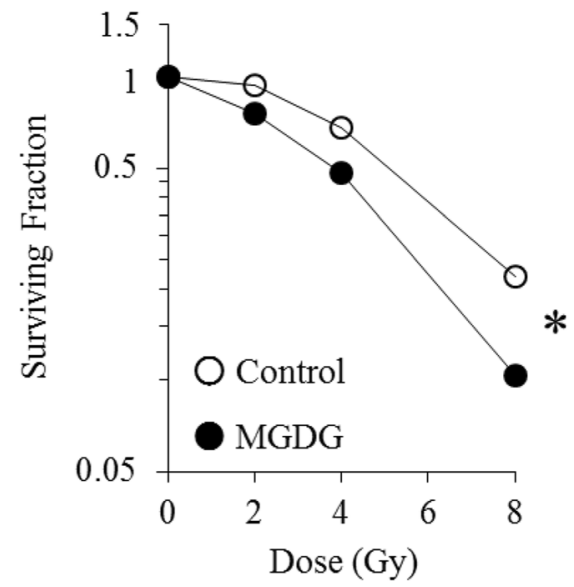

(c)
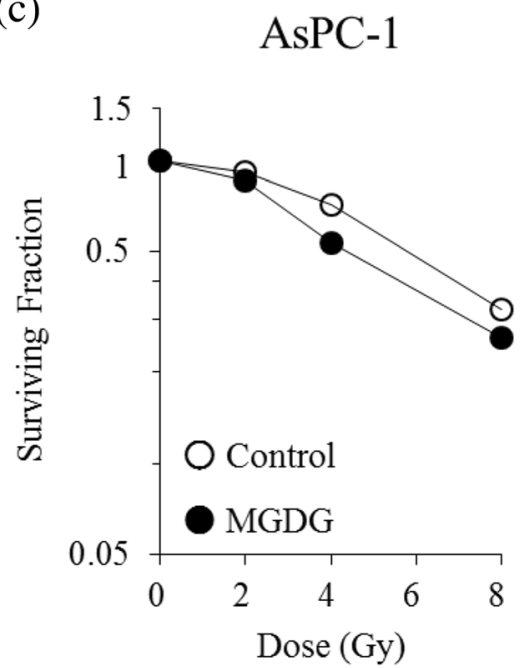

(b)

\section{BxPC-3}

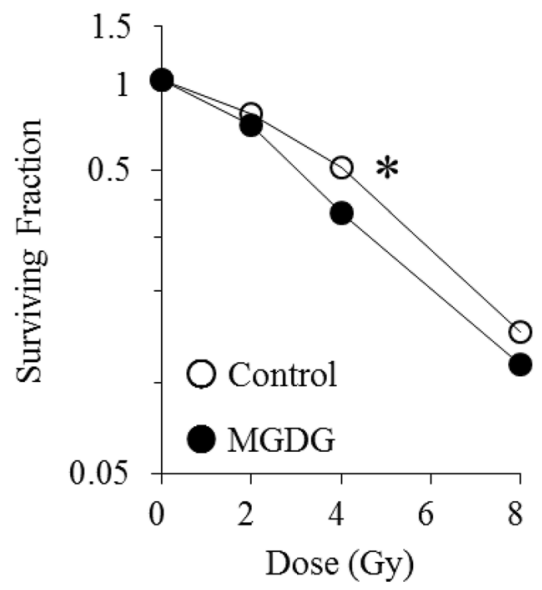




\section{Results}

Cell viability

Compared to DGDG or SQDG, MGDG showed distinct cytotoxic effects on human cancer cell growth (Table 1). MGDG showed dose- and time-dependent cytotoxicity in all four human pancreatic cancer cell lines, as determined with the MTT assay (Fig. 1a). The half-maximal inhibitory concentrations $\left(\mathrm{IC}_{50}\right)$ in MIAPaCa-2, BxPC-3, AsPC-1 and PANC- 1 cells at $72 \mathrm{~h}$ were $18.5 \pm 1.7,26.9$ $\pm 1.3,22.7 \pm 1.9$, and $25.6 \pm 2.5 \mu \mathrm{M}$, respectively. In contrast, MGDG showed almost no cytotoxicity in NHDFs, and combined MGDG treatment and irradiation did not have a synergistic effect in NHDFs as compared to irradiation alone (Fig. 1b). The colony forming assay revealed fewer MIAPaCa-2, BxPC-3 and AsPC-1 cell colonies upon treatment with the combination treatment as compared to irradiation alone $(P<0.05)$ (Fig. 2).

\section{Induction of apoptosis}

The single treatments increased the rate of apoptosis (5.2\% for MGDG and 8.8\% for radiation), while the combination of both yielded a higher proportion of apoptotic cells $(21.5 \%)$, suggesting that they had a synergistic effect on apoptosis induction (Fig. 3).

Molecular events underlying apoptosis in MIAPaCa-2 cells treated with MGDG were investigated by the western blotting. Cytochrome c release from mitochondria to the cytosol increased in a concentration-dependent manner in the presence of 50 and $75 \mu \mathrm{M}$ of MGDG; that is, cytochrome c level was reduced in mitochondria and increased in the cytosol relative to control cells (Fig. 4a, b). The activation of cleaved PARP and cleaved caspase- 3 was also increased by MGDG treatment (Fig. 4c, d), with the latter possibly resulting from increased mitochondrial release of cytochrome c. Bax was also upregulated in a dosedependent manner at 25 an $50 \mu \mathrm{M}$, whereas Bcl-2 level remained largely unaffected $(P<0.05)$ (Fig. 4 e, f). A possible reason for slight decrease in Bax and Bcl-2 levels at $75 \mu \mathrm{M}$ MGDG is cell loss caused by severe MGDG toxicity. Results from the western blot analysis were compared with the Student's $t$ test [22].

\section{DNA damage and DNA repair impairment}

The effects of MGDG and radiation on the cellular DNA damage response was evaluated by quantifying $\gamma$ $\mathrm{H} 2 \mathrm{AX}$ foci in MIAPaCa-2 cells. Compared to irradiation alone, combination treatment increased the number of $\gamma$-H2AX foci in MIAPaCa-2 cells (Fig. 5a, b). The results indicate that MGDG and irradiation induce DNA damage in a synergistic manner.

We performed the alkaline comet assay to detect defects in DNA repair. At 30min, the proportion of comet tails indicating DNA fragments was higher in the combination treatment (46.5\%) than in the MGDG (3.2\%) and irradiation $(30.5 \%)$ groups $(P<0.05)$ (Fig. 5c). At later time points, most cells had completed DNA repair or had undergone apoptosis. These results indicate that MGDG potentiated the suppressive effects of radiation on DNA repair.

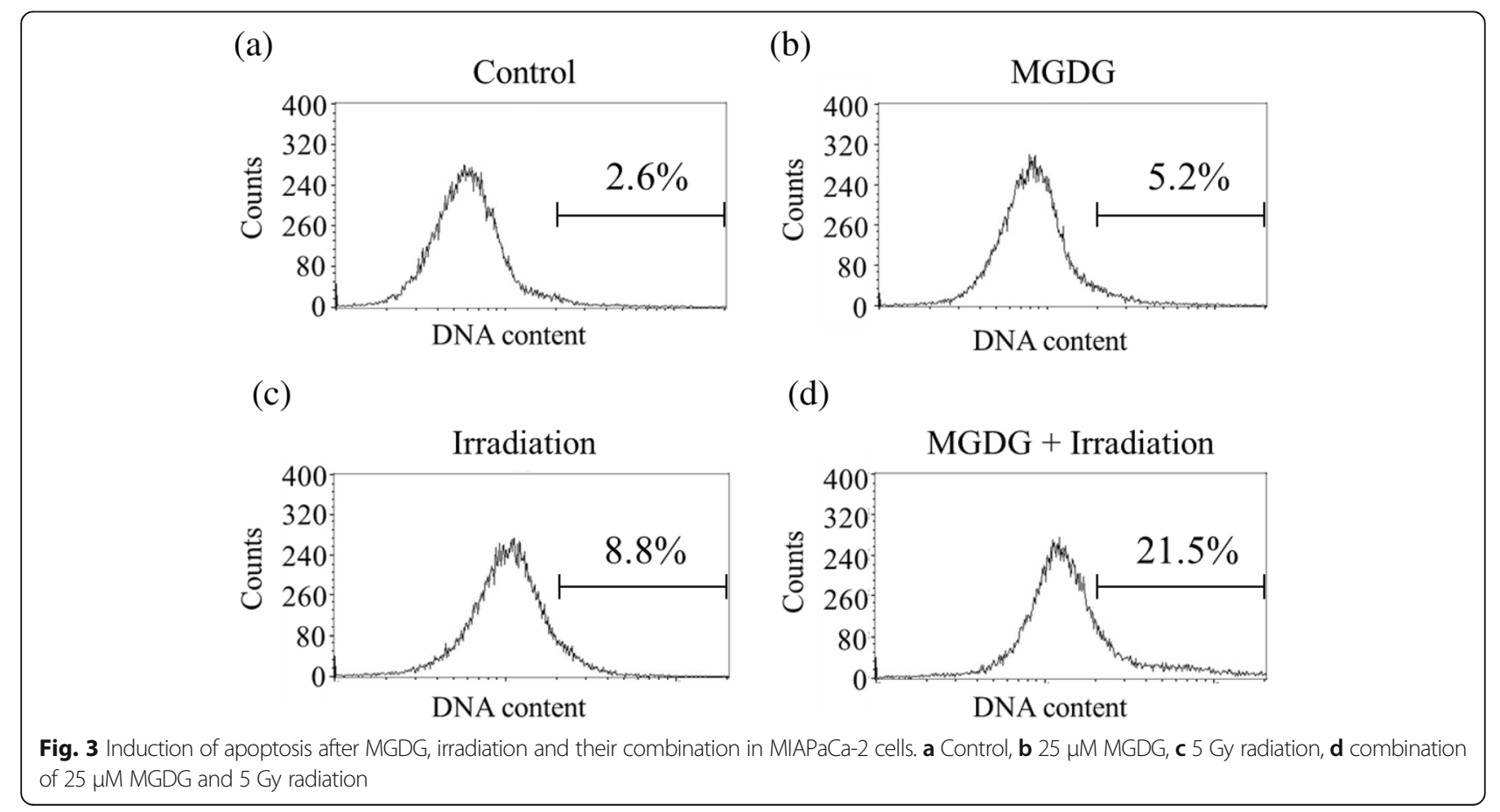


(a)

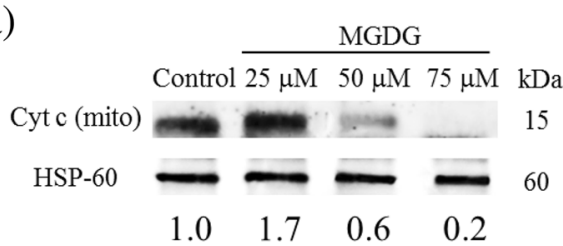

(c)

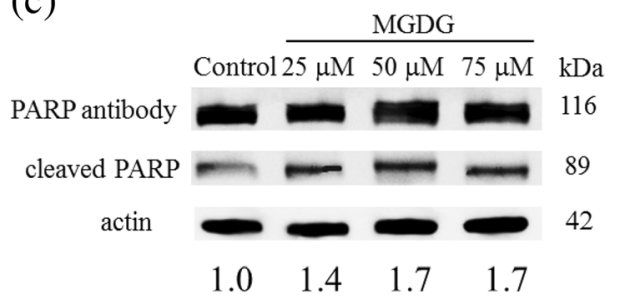

(e)

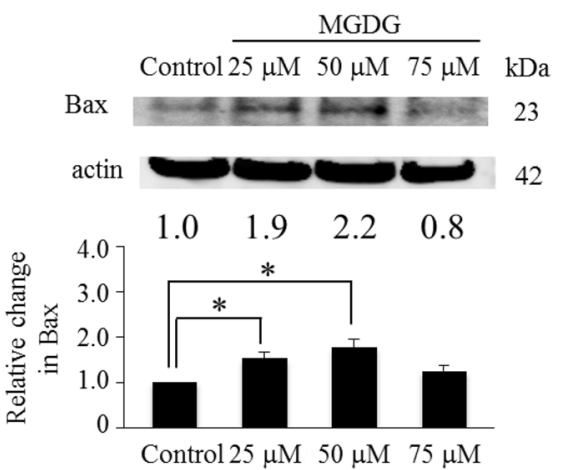

(b)

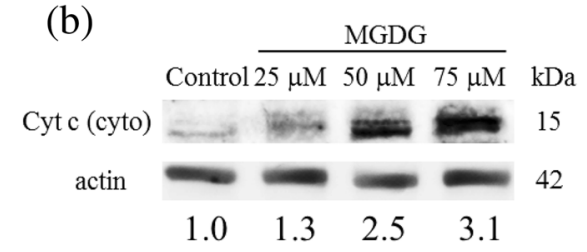

(d)

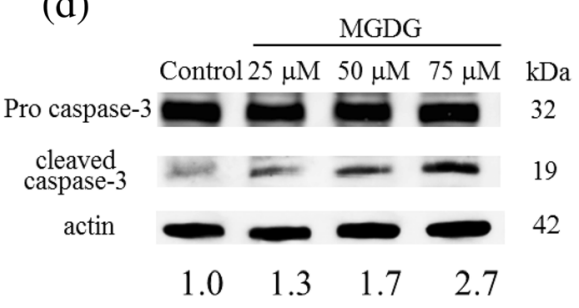

(f)
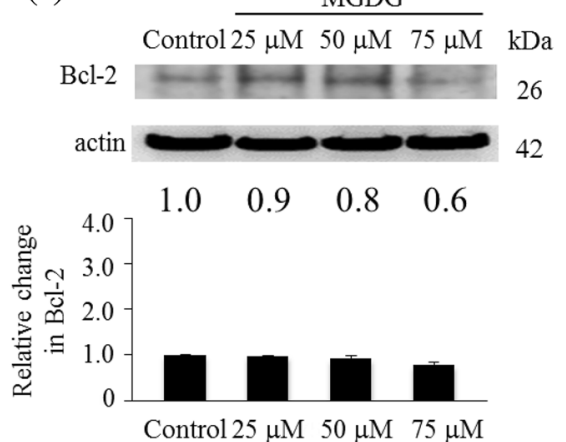

Fig. 4 Molecular events underlying apoptosis in MIAPaCa-2 cells treated with MGDG. a Cytochrome $\mathrm{c}$ in mitochondria, b Cytochrome $\mathrm{c}$ in the cytosol, c PARP and cleaved PARP, c Pro caspase-3 and cleaved caspase-3, e Bax and $\mathbf{f} \mathrm{Bcl}-2$ levels were determined by western blotting. Protein levels were evaluated relative to HSP-60 or actin. ${ }^{*} P<0.05$

\section{Cell cycle distribution}

To determine whether cell cycle was affected by MGDG or irradiation, MIAPaCa-2 cell cycle distribution was analyzed by flow cytometry. MGDG induced a slight increase in the G2/M fraction (29.9-36.2\%) (Fig. 6a, b), while irradiation caused G2/M arrest (29.9-65.3\%) (Fig. 6a, c). The cell cycle distribution following combination treatment was similar to that of irradiation alone (Fig. 6c, d). These results indicate that MGDG does not act synergistically with radiation to induce cell cycle arrest.

\section{Tumor growth inhibitory effect}

The effects of MGDG and radiation were assessed in a mouse xenograft model using MIAPaCa-2 cells. After 23 days, the tumor volumes were $7475.3 \pm 986.1 \mathrm{~mm}^{3}$ (control), $\quad 7598.8 \pm 1532.0 \mathrm{~mm}^{3} \quad$ (MGDG), $5892.7 \pm$ $1313.3 \mathrm{~mm}^{3}$ (radiation), and $2539.8 \pm 552.7 \mathrm{~mm}^{3}$ (MGDG and radiation) (Fig. 7a, b). The tumor growth inhibitory effect was greater in mice receiving intratumoral injection of MGDG combined with irradiation as compared to either of these approaches alone $(P<0.05)$ (Fig. 7b).

\section{Discussion}

In our previous study, MGDG was found to selectively inhibit mammalian pols $\alpha, \gamma, \delta$ and $\varepsilon$ while having no effect on other mammalian pols, such as those related to repair $(\beta, \eta, \mathrm{l}, \kappa, \lambda$ and $\mu)$ or terminal deoxynucleotidyl transferase activities [21]. In the present study, we found that MGDG suppressed proliferation of various cancer cell types, including pancreatic cancer cells. Given that the $50 \%$ lethal dose $\left(\mathrm{LD}_{50}\right)$ for suppression of cell growth by MGDG is nearly equivalent to the $\mathrm{IC}_{50}$ for inhibition of polymerase activities, we speculate that MGDG penetrates cancer cells and inhibits the activities of mammalian nuclear DNA repair pols $\delta$ and $\varepsilon$ as well as the mitochondrial DNA repair pol $\gamma$, leading to radiosensitization and cell growth suppression. We also compared the growthinhibitory effects of MGDG with those of other spinach glycoglycerolipids in several cancer cell lines (Table 1). 
(a)
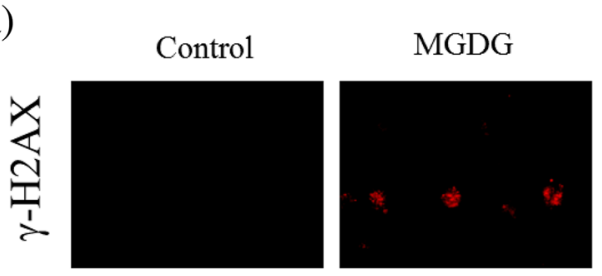

Irradiation

MGDG + Irradiation
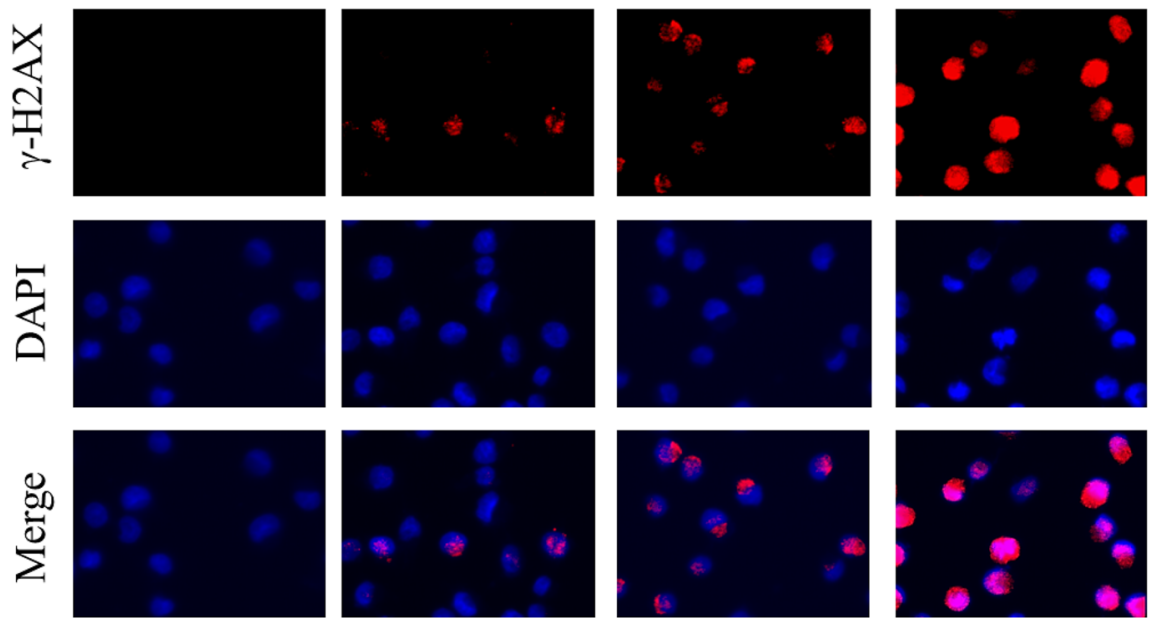

(b)

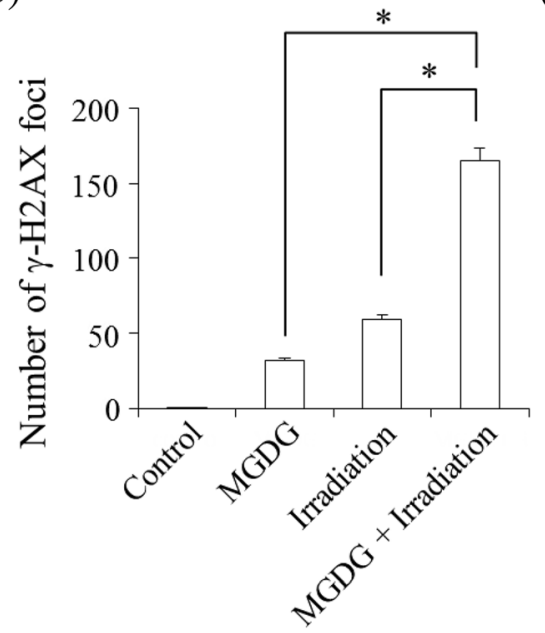

(c)

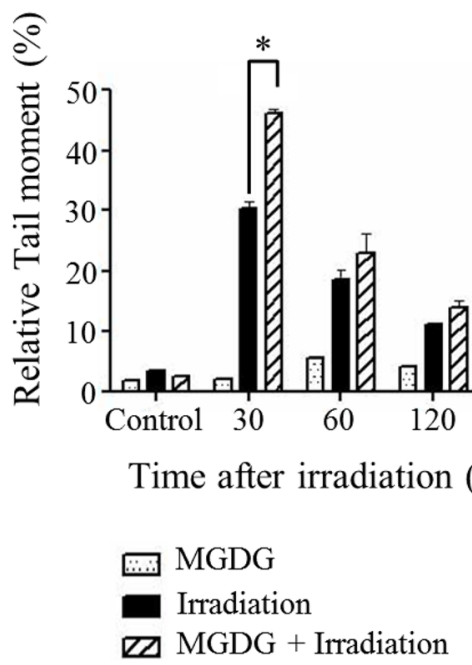

Fig. 5 DNA damage and repair in MIAPaCa-2 cells after MGDG (25 $\mu \mathrm{M}$ for $24 \mathrm{~h}$ ), radiation (8 Gy for $12 \mathrm{~h}$ ), or both. a Detection of DNA damage by $\mathrm{Y}-\mathrm{H} 2 \mathrm{AX}$ foci staining. b Quantification of $\mathrm{Y}$-H2AX-positive cells. c Comet assay for detection of DNA fragments. ${ }^{*} P<0.05$

Interestingly, the MGDG had more potent cytotoxic effects than these two compounds in all cell types examined, consistent with a previous report [9].

Pancreatic cancer is a lethal disease; the 5-year survival rate is approximately $3-7 \%$ following diagnosis $[1,2]$. Surgical resection is the only curative treatment but the majority of patients are diagnosed at late, inoperable stages. Locally advanced pancreatic cancer (LAPC) is resistant to many forms of chemoradiotherapy (CRT) [3]. CRT with concurrent 5-fluorouracil was previously considered as a standard treatment for LAPC $[25,26]$. More recently, based on favorable responses to GEM-based chemotherapy $[27,28]$ and the observation that GEM is a potent radiosensitizer [29], GEM-concurrent CRT has been used to treat LAPC [30, 31], with improved survival rates. Since conventionally fractionated chemoradiotherapy is associated with 1-year local control rates of only $40-60 \%$, a strategy to enhance the effects of radiation is necessary. To this end, our observation of radiosensitization by MGDG suggests that it can be a possible treatment option for LAPC. A recent study reported successful results by combining GEM with proton therapy to treat LAPC; the 1-year local progression-free and overall survival rates were 81.7 and $76.8 \%$, respectively [32]. Alternatively, stereotactic body radiation therapy can potentially achieve high local controllability in the management of pancreatic cancer [33, 34]. However, these methods have also been associated with a high incidence of acute morbidity [32, 33]. Given that MGDG enhances the effects of GEM in pancreatic cancer cell 
(a)

Control

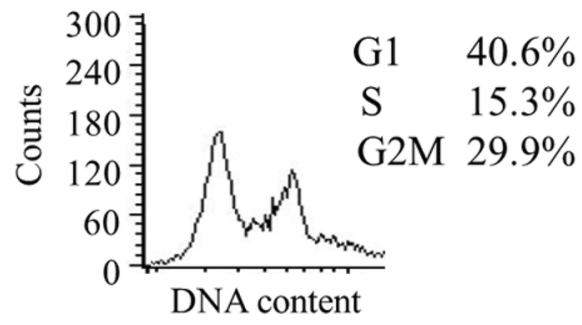

(c)

Irradiation

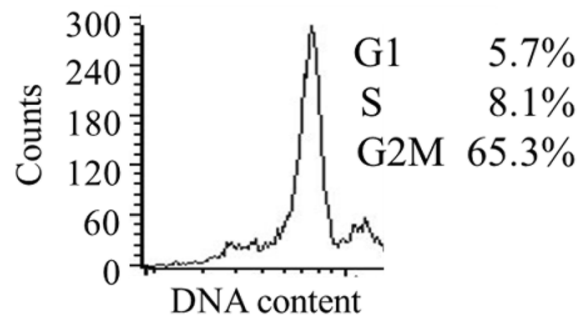

(b)

MGDG

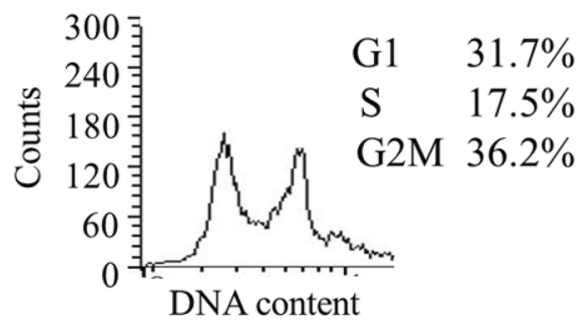

(d)

$$
\text { MGDG + Irradiation }
$$

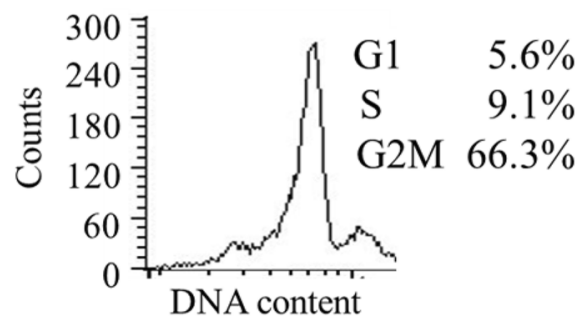

Fig. 6 Cell cycle distribution in MIAPaCa-2 cells after treatment with MGDG, radiation or both. a Control, b MGDG (25 $\mu \mathrm{M}$ for 24 h), c radiation ( 8 Gy for $12 \mathrm{~h}$ ), and $\mathbf{d}$ combination of $25 \mu \mathrm{M} \mathrm{MGDG}$ for $24 \mathrm{~h}$ and 8 Gy radiation for $12 \mathrm{~h}$

(a)
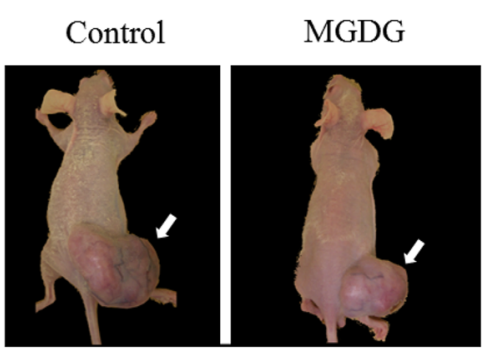

Irradiation

MGDG + Irradiation

(b)

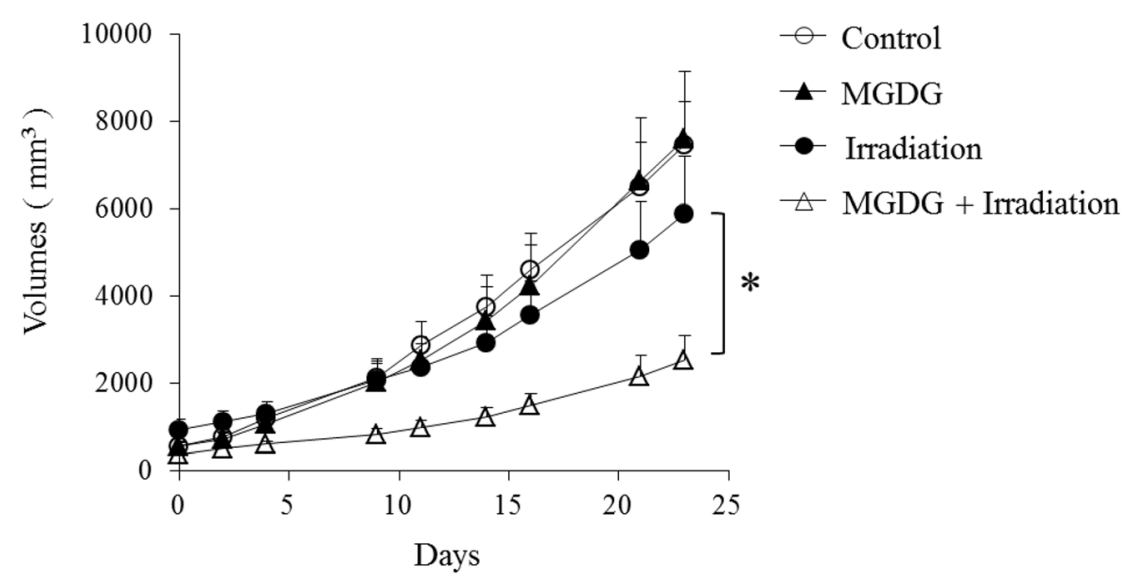

Fig. 7 Tumor growth inhibitory effect of MGDG combined with irradiation. a Tumor appearance in xenografts 23 days after treatment (arrowhead). b Sequential measurements of tumor size after each treatment. Data are shown as mean \pm SE. ${ }^{*} P<0.05$ 
lines [21] as well as those of irradiation in this study, the therapeutic efficacy of MGDG combined with a lower dose of GEM or with radiotherapy should be tested as a means of reducing the morbidity of chemoradiotherapy for LAPC.

Most chemotherapeutic agents do not significantly improve the survival of pancreatic cancer patients [35]. Dysregulation of pro-apoptosis signaling is a survival mechanism for pancreatic cancers. Given that nearly every step of carcinogenesis inhibits apoptosis, the development of therapeutic strategies that target this process is essential for effective treatment of pancreatic cancer [36]. MGDG was recently introduced as a novel anticancer agent that can potentially increase apoptosis rates in human cancer cell lines. We previously showed that combining MGDG and GEM induced cell death and apoptosis [21]. In this study, MGDG showed dosedependent cytotoxicity in pancreatic cancer cell lines, as evidenced by increased mitochondrial cytochrome c release and activation of caspase- 3 followed by PARP, which resulted in apoptosis. Radiation causes DNA damage and kills mammalian cells by inducing single- and double-strand breaks in DNA [37]. The fact that the combination treatment showed greater cytotoxicity in vitro and in vivo than either approach alone indicates that the inhibitory effects of radiation on DNA are synergistically enhanced by MGDG.

MGDG alone or combined with radiation had negligible cytotoxicity in NHDFs as determined by the MTT assay, which is consistent with previous findings [21]. We used this as opposed to the colony forming assay since these cells did not form measurable colonies. However, one limitation of this study is that the possible side effects of MGDG were not fully investigated; specifically, the toxicity at high doses caused by its inhibition of DNA polymerase activity warrants further investigation. The side effects of MGDG are presumably similar to those caused by pyrimidine analogs such as GEM and cytarabine. GEM is widely used to treat various types of malignancy including non-small cell lung and breast cancers and is a key drug for the treatment of pancreatic cancer [38]. An in vivo model in which various doses are tested followed by a phase I clinical study can clarify the potential side effects of MGDG. Another limitation is that administration of MGDG was tested by intratumoral injection. In an earlier study, tumor growth was slightly inhibited by the oral administration of spinach glycolipid fractions containing MGDG, DGDG and SQDG [8]; however, oral administration of a single compound (e.g., MGDG) combined with irradiation has not been previously assessed. Using different modes of administration could potentially clarify the efficacy of MGDG for the treatment of pancreatic cancer.

\section{Conclusions}

This is the first report providing evidence that MGDG enhances the cytotoxic effects of radiation in pancreatic cancer cells in vitro and in vivo. This effect is likely associated with stimulation of mitochondrial cytochrome c release. Combined treatment with MGDG and radiation synergistically suppressed tumor growth in vivo. Our findings indicate that this therapeutic combination can be an effective strategy for the treatment of pancreatic cancer.

\begin{abstract}
Abbreviations
BCl-2: B cell lymphoma-2; CRT: Chemoradiotherapy; DGDG: Digalactosyl diacylglycerol; DMSO: Dimethylsulfoxide; FITC: Fluorescein isothiocyanate; GEM: Gemcitabine; IC $\mathrm{C}_{50}$ : Half maximal (50\%) inhibitory concentration; LAPC: Locally advanced pancreatic cancer; MGDG: Monogalactosyl diacylglycerol; MTT: 3-(4,5-dimethylthiazol-2-yl)-2,5-diphenyltetrazolium bromide; NHDF: Primary normal human dermal fibroblast; PARP: Poly (ADP-ribose) polymerase; PBS: Phosphate-buffered saline; PBST: PBS containing $0.05 \%$ Tween; SQDG: Sulfoquinovosyl diacylglycerol; $\gamma^{-}$ H2AX: Phosphorylated histone 2AX
\end{abstract}

\section{Acknowledgments}

The authors thank Izumi Takayama and Makiko Nakahana (Division of Radiation Oncology, Kobe University) for technical assistance.

\section{Funding}

This work was supported by Grants-in-Aid (nos. 16K15581 and 16H05391 to RS and no. 16K19818 to NM) for Exploratory Research from the Ministry of Education, Culture, Sports, Science and Technology of Japan.

\section{Availability of data and materials}

Datasets supporting the conclusions of this study are included within the article.

\section{Authors' contributions}

HA and RS contributed to study conception and design. HA, NM, TW and MN performed the experiments and acquired the data. YM contributed technical and material support. YW performed the DNA damage assay. HA, $\mathrm{RS}, \mathrm{KY}, \mathrm{YE}$ and SI participated in the analysis and interpretation of data. All authors read and approved the final manuscript.

\section{Competing interests}

The authors declare that they have no competing interests.

\section{Consent for publication}

Not applicable.

\section{Ethics approval}

Animal experiments in this study were approved by the Institutional Animal Care and Use Committee (permission no. 100605R1) and were performed according to Kobe University Animal Experimentation regulations.

\footnotetext{
Author details

${ }^{1}$ Division of Radiation Oncology, Kobe University Graduate School of Medicine, Chuo-ku, Kobe, Hyogo 650-0017, Japan. ${ }^{2}$ Graduate School of Agriculture, Shinshu University, Minamiminowa-mura, Kamiina-gun, Nagano 399-4598, Japan.

Received: 5 July 2016 Accepted: 15 November 2016

Published online: 22 November 2016

\section{References}

1. Siegel RL, Miller KD, Jemal A. Cancer statistics, 2015. CA Cancer J Clin. 2015; 65:5-29.

2. Sharma C, Eltawil KM, Renfrew PD, Walsh MJ, Molinari M. Advances in diagnosis, treatment and palliation of pancreatic carcinoma: 1990-2010. World J Gastroenterol. 2011;17:867-97.
} 
3. Goodman KA, Hajj C. Role of radiation therapy in the management of pancreatic cancer. J Surg Oncol. 2013;107:86-96.

4. Terry P, Giovannucci E, Michels KB, Bergkvist L, Hansen H, Holmberg L, et al. Fruit, vegetables, dietary fiber, and risk of colorectal cancer. J Natl Cancer Inst. 2001;93:525-33.

5. Surh Y-J. Cancer chemoprevention with dietary phytochemicals. Nat Rev Cancer. 2003;3:768-80

6. Liu RH. Potential synergy of phytochemicals in cancer prevention: mechanism of action. J Nutr. 2004;134:3479-85.

7. Maeda N, Yoshida H, Mizushina Y. Spinach and health: anti-cancer effect. In: Preedy VR, editor. Bioactive foods in promoting health. San Diego: Academic; 2010. p. 393-405.

8. Maeda N, Kokai Y, Ohtani S, Sahara H, Kumamoto-Yonezawa Y, Kuriyama I, et al. Anti-tumor effect of orally administered spinach glycolipid fraction on implanted cancer cells, Colon-26, in mice. Lipids. 2008;43:741-8.

9. Maeda N, Matsubara K, Yoshida H, Mizushina Y. Anti-cancer effect of spinach glycoglycerolipids as angiogenesis inhibitors based on the selective inhibition of DNA polymerase activity. Mini Rev Med Chem. 2011;11:32-8.

10. Sugawara T, Miyazawa T. Separation and determination of glycolipids from edible plant sources by high-performance liquid chromatography and evaporative light- scattering detection. Lipids. 1999;34:1231-7.

11. Yunoki K, Sato M, Seki K, Ohkubo T, Tanaka Y, Ohnishi M. Simultaneous quantification of plant glyceroglycolipids including sulfoquinovosyldiacylglycerol by HPLC-ELSD with binary gradient elution. Lipids. 2009;44:77-83.

12. Kuriyama I, Musumi K, Yonezawa Y, Takemura M, Maeda N, lijima H, et al. Inhibitory effects of glycolipids fraction from spinach on mammalian DNA polymerase activity and human cancer cell proliferation. J Nutr Biochem. 2005;16:594-601.

13. Cascinu S, Falconi M, Valentini V, Jelic S, ESMO Guidelines Working Group. Cancer of the pancreas: ESMO clinical practice guidelines for diagnosis, treatment and follow-up. Ann Oncol. 2015;21 Suppl 5:v55-8.

14. Oettle H, Neuhaus P, Hochhaus A, Hartmann JT, Gellert K, Ridwelski K, et al. Adjuvant chemotherapy with gemcitabine and long-term outcomes among patients with resected pancreatic cancer: the CONKO-001 randomized trial. JAMA. 2013;310:1473-81

15. Neoptolemos JP, Stocken DD, Bassi C, Ghaneh P, Cunningham D, Goldstein D, Padbury R, Moore MJ, Gallinger S, Mariette C, Wente MN, Izbicki JR, Friess H, European Study Group for Pancreatic Cancer, et al. Adjuvant chemotherapy with fluorouracil plus folinic acid vs gemcitabine following pancreatic cancer resection: a randomised controlled trial. JAMA. 2010;304:1073-81.

16. Andriulli A, Festa V, Botteri E, Valvano MR, Koch M, Bassi C, et al. Neoadjuvant/ preoperative gemcitabine for patients with localized pancreatic cancer: a Metaanalysis of prospective studies. Ann Surg Oncol. 2012;19:1644-62.

17. Assifi MM, Lu X, Eibl G, Reber HA, Li G, Hines OJ. Neoadjuvant therapy in pancreatic adenocarcinoma: a Meta-analysis of phase II trials. Surgery. 2011; 150:466-73.

18. Laurence JM, Tran PD, Morarji K, Eslick GD, Lam WW, Sandroussi C. A systematic review and meta-analysis of survival and surgical outcomes following neoadjuvant chemoradiotherapy for pancreatic cancer. J Gastrointest Surg. 2011;15:2059-69.

19. Huguet F, André T, Hammel P, Artru P, Balosso J, Selle F, et al. Impact of chemoradiotherapy after disease control with chemotherapy in locally advanced pancreatic adenocarcinoma in GERCOR phase II and III studies. J Clin Oncol. 2007;25:326-31.

20. Krishnan S, Rana V, Janjan NA, Varadhachary GR, Abbruzzese JL, Das P, et al. Induction chemotherapy selects patients with locally advanced, unresectable pancreatic cancer for optimal benefit from consolidative chemoradiation therapy. Cancer. 2007;110:47-55.

21. Akasaka H, Sasaki R, Yoshida K, Takayama I, Yamaquchi T, Yoshida H, et al. Monogalactosyl diacylglycerol, a replicative DNA polymerase inhibitor, from spinach enhances the anti-cell proliferation effect of gemcitabine in human pancreatic cancer cells. Biochim Biophys Acta. 1830;2013:2517-25.

22. Mukubou H, Tsujimura T, Sasaki R, Ku Y. The role of autophagy in the treatment of pancreatic cancer with gemcitabine and ionizing radiation. Int J Oncol. 2010;37:821-8.

23. Sasaki R, Shirakawa T, Zhang ZJ, Tamekane A, Matsumoto A, Sugimura K, et al. Additional gene therapy with Ad5CMV-p53 enhanced the efficacy of radiotherapy in human prostate cancer cells. Int J Radiat Oncol Biol Phys. 2001;51:1336-45.

24. Nakayama M, Sasaki R, Ogino C, Tanaka T, Morita K, Umetsu M, et al. Titanium peroxide nanoparticles enhanced cytotoxic effects of $X$-ray irradiation against pancreatic cancer model through reactive oxygen species generation in vitro and in vivo. Radiat Oncol. 2016;11:91.

25. GITSG. Treatment of locally unresectable carcinoma of the pancreas: comparison of combined-modality therapy (chemotherapy plus radiotherapy) to chemotherapy alone. Gastrointestinal Tumor Study Group. J Natl Cancer Inst. 1988;80:751-5.

26. Moertel CG, Frytak S, Hahn RG, O'Connell MJ, Reitemeier RJ, Rubin J, et al. Therapy of locally unresectable pancreatic carcinoma: a randomized comparison of high dose (6000 rads) radiation alone, moderate dose radiation (4000 rads + 5-fluorouracil), and high dose radiation + 5-fluorouracil: The Gastrointestinal Tumor Study Group. Cancer. 1981:48:1705-10.

27. Burris 3rd HA, Moore MJ, Andersen J, Green MR, Rothenberg ML, Modiano $M R$, et al. Improvements in survival and clinical benefit with gemcitabine as first-line therapy for patients with advanced pancreas cancer: a randomized trial. J Clin Oncol. 1997:15:2403-13.

28. Ishii H, Furuse J, Boku N, Okusaka T, Ikeda M, Ohkawa S, et al. Phase II study of gemcitabine chemotherapy alone for locally advanced pancreatic carcinoma: JCOG0506. Jpn J Clin Oncol. 2010;40:573-9.

29. Lawrence TS, Eisbruch A, McGinn CJ, Fields MT, Shewach DS. Radiosensitization by gemcitabine. Oncology (Williston Park). 1999;13:55-60.

30. Huang PI, Chao Y, Li CP, Lee RC, Chi KH, Shiau CY, et al. Efficacy and factors affecting outcome of gemcitabine concurrent chemoradiotherapy in patients with locally advanced pancreatic cancer. Int J Radiat Oncol Biol Phys. 2009;73:159-65.

31. Murphy JD, Adusumilli S, Griffith KA, Ray ME, Zalupski MM, Lawrence TS, et al. Full-dose gemcitabine and concurrent radiotherapy for unresectable pancreatic cancer. Int J Radiat Oncol Biol Phys. 2007;68:801-8.

32. Terashima K, Demizu Y, Hashimoto N, Jin D, Mima M, Fujii O, et al. A phase I//l study of gemcitabine-concurrent proton radiotherapy for locally advanced pancreatic cancer without distant metastasis. Radiother Oncol. 2012;103:25-31.

33. Koong AC, Le QT, Ho A, Fong B, Fisher G, Cho C, et al. Phase I study of stereotactic radiosurgery in patients with locally advanced pancreatic cancer. Int J Radiat Oncol Biol Phys. 2004;58:1017-21.

34. Chuong MD, Springett GM, Freilich JM, Park CK, Weber JM, Mellon EA, et al. Stereotactic body radiation therapy for locally advanced and borderline resectable pancreatic cancer is effective and well tolerated. Int I Radiat Oncol Biol Phys. 2013;86:516-22.

35. Van Laethem JL, Verslype C, lovanna JL, Michl P, Conroy T, Louvet C, et al. New strategies and designs in pancreatic cancer research: consensus guidelines report from a European expert panel. Ann Oncol. 2012;23:570-6.

36. Hamacher R, Schmid RM, Saur D, Schneider G. Apoptotic pathways in pancreatic ductal adenocarcinoma. Mol Cancer. 2008;7:64.

37. Vignard J, Mirey G, Salles B. lonizing-radiation induced DNA double-strand breaks: a direct and indirect lighting up. Radiother Oncol. 2013;108:362-9.

38. de Sousa Cavalcante L, Monteiro G. Gemcitabine: metabolism and molecular mechanisms of action, sensitivity and chemoresistance in pancreatic cancer. Eur J Pharmacol. 2014;741:8-16.

\section{Submit your next manuscript to BioMed Central and we will help you at every step:}

- We accept pre-submission inquiries

- Our selector tool helps you to find the most relevant journal

- We provide round the clock customer support

- Convenient online submission

- Thorough peer review

- Inclusion in PubMed and all major indexing services

- Maximum visibility for your research

Submit your manuscript at www.biomedcentral.com/submit

) Biomed Central 